\title{
Cellular Signaling Mechanisms of Hypocretin/Orexin
}

\author{
Jyrki P. Kukkonen Pauli M. Turunen \\ Department of Pharmacology and Department of Physiology, Institute of Biomedicine, Faculty of \\ Medicine, University of Helsinki, Helsinki, Finland
}

\begin{abstract}
Orexin receptors (OXRs) are promiscuous G-protein-coupled receptors that signal via several G-proteins and, putatively, via other proteins. On which basis the signal pathways are selected and orchestrated is largely unknown. We also have an insufficient understanding of the kind of signaling that is important for specific types of cellular responses. OXRs are able to form complexes with several other G-proteincoupled receptors in vitro, and one possibility is that the complexing partners regulate the use of certain signal transducers. In the central nervous system neurons, the main acute downstream responses of OXR activation are the inhibition of $\mathrm{K}^{+}$channels and the activation of the $\mathrm{Na}^{+} / \mathrm{Ca}^{2+}$ exchanger and nonselective cation channels of unknown identity. The exact nature of the intracellular signal chain between the OXRs and these downstream targets is yet to be elucidated, but the $\mathrm{G}_{\mathrm{q}}$-phospholipase C (PLC) protein kinase $C$ pathway - which is a significant signaling pathway for OXRs in recombinant cells - may be one of the players in neurons. The $\mathrm{G}_{\mathrm{q}}-\mathrm{PLC}$ pathway may also, under certain circumstances, take the route to diacylglycerol lipase, which leads to the production of the potent endocannabinoid (eCB), 2-arachidonoyl glycerol, and thereby connects orexins with eCB signaling. In addition, OXRs have been studied in the context of neurodegeneration and cancer cell death. Overall, OXR signaling is complex, and it can change depending on the cell type and environment.

(C) 2021 The Author(s)

Published by S. Karger AG, Basel
\end{abstract}

\section{Introduction}

The aim of this chapter is to focus on the molecular players in the cellular responses to orexin receptor (OXR) activation. As we have previously reviewed this in detail [1-7], we will draw on the basics of the signaling and provide an update on recent developments. 
We need to apply certain criteria in selecting our information. First, there has to be a direct demonstration that OXR signaling is either distorted or affected, as pathway inhibitors often lack specificity. We must further consider that permissive background signaling pathways may be required for the readout response, and that their inhibition may also inhibit the "orexin-specific signal." In neurobiology, we clearly need to be more liberal, as there are no methods to measure the signals in those very few cells targeted, but the approaches still need to make sense. The second criterion is that the signaling proposed needs to be logical, and if not, an explanation or a hypothesis provided. Third, the methods of the study need to be fully described and validated.

\section{G-Proteins and Other Potential Interaction Partners and Signal Transducers for Orexin Receptors}

The OXRs $\mathrm{OX}_{1} \mathrm{R}$ and $\mathrm{OX}_{2} \mathrm{R}$ are G-protein-coupled receptors (GPCRs). They display the typical signaling via heterotrimeric G-proteins [4]. However, only a few studies have directly investigated the primary coupling of these receptors (reviewed in $[4,6]$; for examples, see [8-13]). The reason is that good and specific tools for such investigations are both scarce and difficult to apply. Some studies rely on the interpretation of the downstream signal readouts being indicative of particular G-protein pathways, which is rarely a simple or unequivocal approach, and especially transcription factor-based readouts cannot be linked to a specific G-protein. Dominant-negative G-proteins are not specific [14]. OXRs are thought to belong to the promiscuous GPCRs, i.e. they can signal via G-proteins from three subfamilies $[4,6]$. This is typical for GPCRs, but we do not know what decides which G-proteins are activated in which tissue. No evidence shows significantly different signaling of the two OXR subtypes.

The availability and recruitment of the primary signal transducers decide which kind of cellular signal(s) the receptor generates, and the co-produced signals may be both divergent and convergent. Identification of the signal transducers provides us with basic physiological information of the spectrum of the receptor signals and the regulation of the subsequent signaling components. For a number of GPCRs, so-called biased signaling, i.e. the preferential activation of different signal pathways by chemically different ligands, has been reported [14-16], supporting the idea that several types of G-proteins (and other signal transducers) may be able to interact with a single GPCR. Biased signaling is a therapeutically attractive approach to promote particular signals without activating other ones. An example of much interest is the development of opioid receptor agonists that would not activate the $\beta$-arrestin pathway, thus potentially avoiding receptor desensitization and physiological tolerance [17].

We have investigated the potential of OXRs for biased signaling using the native agonists orexin-A and orexin-B and the synthetic agonists $\mathrm{Ala}^{11}$ - $\mathrm{dLeu}^{15}$-orexin-B and Nag 26 ( $4^{\prime}$-methoxy-N,N-dimethyl-3'-[N-(3-\{[2-(3-methylbenzamido)ethyl]amino\}phenyl) sulfamoyl]-(1, $1^{\prime}$-biphenyl)-3-carboxamide. We first observed that the relative agonist po- 
tencies for the $\mathrm{G}_{\mathrm{q}}$-dependent calcium responses were different in $\mathrm{CHO}$ (Chinese hamster ovary K1) and HEK293 (a human embryonic kidney cell line) cells [18]. Further, different $\mathrm{G}_{\mathrm{q}}$-dependent responses gave inconsistent relative potencies when assessing orexin- $\mathrm{A}$ and $\mathrm{Nag} 26$ in $\mathrm{OX}_{1} \mathrm{R}$ - and $\mathrm{OX}_{2} \mathrm{R}$-expressing $\mathrm{CHO}-\mathrm{K} 1$ cells [19]. Possible explanations for these observations could include the presence of different thresholds, amplification and cut-off levels for different readouts [5], and that several G-protein pathways contribute to each readout. In agreement with this, we have previously observed unexplained collaboration between two different G-protein signaling pathways for OXRs [20]. The agonist Nag 26 which, for the apparent $\mathrm{G}_{\mathrm{q}}$ responses prefers $\mathrm{OX}_{2} \mathrm{R}$, shows $\mathrm{OX}_{1} \mathrm{R}$ preference for the apparent $\mathrm{G}_{\mathrm{s}}$ response [19]. These studies, as discussed by Putula et al. [18], indicate biased signaling of OXRs.

One significant issue is that often, we do not know which signal cascade is the most relevant for the response we want to achieve for therapeutic purposes. This applies for narcolepsy or any other pathology of the orexin system. Several studies, and even reviews, infer that the major primary signaling transducer for OXR is $\mathrm{G}_{\mathrm{q}}[4]$. However, this is based solely on the original finding of a significant coupling of human OXRs to calcium elevation in HEK293 [21]. Additional studies have demonstrated a strong coupling to the classically $\mathrm{G}_{\mathrm{q}}$-mediated responses, $\mathrm{Ca}^{2+}$ elevation and phospholipase $\mathrm{C}$ (PLC) activation, especially in recombinant cells $[4,5]$. We have since shown that the heterologously expressed human OXRs in $\mathrm{CHO}-\mathrm{K} 1$ cells couple to the calcium elevation and a number of other readouts via the $\mathrm{G}_{\mathrm{q}}$ family (use of the toxin UBO-QIC/FR900359) [20]. However, these are recombinant, receptor-overexpressing cells; the calcium signaling of OXRs in these cells is peculiar [4] and the PLC-dependent calcium release is unlikely to be a major response in neurons. The G-protein families $G_{i / o}$ and $G_{s}$ have also been implicated in the OXR signaling (reviewed in $[4,6]$; for examples, see [8-10, 20, 22]).

In neurons, some studies utilize pharmacological inhibitors of downstream signal pathways. In such cases, $\mathrm{G}_{\mathrm{q}}$ is extrapolated from the inhibitory potential of PLC and protein kinase $\mathrm{C}(\mathrm{PKC})$ inhibitors $[2,4,5]$. The available PLC inhibitors are inactive, nonspecific, or even toxic [2]. PKC inhibitors may be more useful, but like most kinase inhibitors, they show relative specificity at best $[23,24]$. PKC isoforms may also be activated via pathways other than the $\mathrm{G}_{\mathrm{q}}-\mathrm{PLC}$ route [25].

In addition to heterotrimeric G-proteins, OXRs couple to the general GPCR companion, $\beta$-arrestin, which may transduce some orexin signals [26-28]. Additional non-receptor proteins suggested to interact with OXRs are the protein tyrosine phosphatase SHP-2 and the dynein light chain Tctex type 3 [29-31]. The former is proposed to be involved in cell death. The melanocortin receptor accessory protein 2 (MRAP2) has been shown to interact with $\mathrm{OX}_{1}$ Rs in recombinant $\mathrm{CHO}-\mathrm{K} 1$ cells [32], and to decrease both the total and plasma membrane expression of $\mathrm{OX}_{1} \mathrm{R}$ and the $\mathrm{OXR}$ signaling, but the latter could be due to the decreased OXR cell surface expression. 


\section{Orexin Receptors in Receptor Complexes}

GPCRs have been suggested to form dimers or oligomers with themselves or other GPCRs [33]. The number of protomers in the complexes is usually unknown, but they are often called dimers, reflecting the methods most often utilized. For OXRs, we have recently reviewed the current knowledge [6, 7]. In brief, both OXR subtypes can form complexes with themselves, each other, and other GPCRs, as demonstrated utilizing many different techniques. In fact, all the GPCRs tested have made complexes with OXRs. Additions to the receptor dimer list since our last review include the following complexes: $\mathrm{OX}_{1}-\mathrm{CCK}_{1}[11], \mathrm{OX}_{1}$-ghrelin [12, 34], $\mathrm{OX}_{1}$-apelin [35], $\mathrm{OX}_{1}-\mathrm{CRF}_{2}$ [36], and $\mathrm{OX}_{2}-5-\mathrm{HT}_{1 \mathrm{~A}}$ [37]. The non-GPCR receptors $\sigma_{1}, \sigma_{2}$, and leptin receptors have also been reported to form complexes with OXRs [34, 36, 38].

Nearly all data are derived from cell lines (CHO-K1 or HEK293) where the receptors had been heterologously expressed. The physiological significance of the data thus remains unknown with regard to (1) the process of formation of the complexes and (2) the physiological co-expression of the receptors investigated. In some cases, the authors justify the studies by suggesting physiological co-expression, but as we know, the anti-OXR antibodies are not reliable ([1]; plenty of our own unpublished studies). Functional interaction may be mistaken for molecular interaction $[39,40]$. The only physiological evidence for the functional OXR complexes thus far concerns $\mathrm{OX}_{1}-\mathrm{CRF}_{1}-\sigma_{1}$ complexes in rat ventral tegmental area [38]. In this study, the authors determined the molecular interaction in vitro. The interaction could be inhibited by a plasma membrane-penetrating peptide fused with isolated $\mathrm{OX}_{1} \mathrm{R}$ transmembrane segments (pepducins). These peptide inhibitors were then used to inhibit the complex formation in vivo [38].

For many GPCRs, signaling in the heteromeric complexes is different from that of homomeric, and this applies also to OXRs $[11,13,37,41]$; maybe the tissue-dependent Gprotein activation by OXRs (and any GPCR) may be explained by the complex partners [7]. Other known properties that are possibly changed by the complexing are receptor pharmacology and trafficking $[42,43]$. For OXRs, we presume that the functional complexes in recombinant cells are di- or oligomeric [44-48]. The only current tools able to inhibit dimerization, pepducins, have not been applied on homomeric OXRs and thus, the role of di-/oligomerization is not known for these, and pepducins may also have offtarget effects [49]. In some cases, the agonists of the receptor protomers are suggested to regulate the complex formation [11, 12, 37, 41, 44, 47, 50-52]. However, the current methods are not well suited for this [6]. Therefore, only one published paper seems to provide clear evidence for the dynamic regulation of OXR complexing [44].

Most of the receptors for which heteromerization with OXRs has been shown are not unequivocally known to be expressed in the same endogenous cells as OXRs. Even more interesting is that some GPCRs of interest, known to be expressed in the same neurons as OXRs, have not been investigated for possible complex formation with OXRs. This includes nearly all the neuronal GPCRs in the orexin target neurons and the receptors in the adrenal cortex, where significant orexin responses have been reported [1], for example the $\mathrm{MC}_{2}$ receptors (adrenocorticotropin receptors). 


\section{Orexin Responses in Different Cell Types}

We have previously reviewed the signaling in neurons and other cell types [4, 5]. In brief, neuronal cells appear to be targets of OXR-mediated depolarization, largely by inhibition of $\mathrm{K}^{+}$channels and activation of $\mathrm{Na}^{+}$influx via $\mathrm{Na}^{+} / \mathrm{Ca}^{2+}$ exchangers and non-selective cation channels $[4,5]$. On a minute-hour timescale after OXR activation, plastic effects take place $[4,5]$. From a molecular perspective, our understanding of neuronal OXR signaling remains limited: we still do not know (1) which G-proteins (or other proteins) are the main signal transducers in neurons, (2) the signaling cascades to $\mathrm{Na}^{+} / \mathrm{Ca}^{2+}$ exchanger and the non-selective cation channels, or (3) the identity of the latter. The selective $\mathrm{G}_{\mathrm{q}}$ inhibitor, UBO-QIC/FR900359 [53, 54], has only been applied to the OXR-expressing recombinant $\mathrm{CHO}-\mathrm{K} 1$ cells [20]. There are also inhibitors with determined profiles for different non-selective cation channels, and we look forward to studies utilizing these. Concerning the signaling cascades further downstream from OXRs, PKC is often identified in neurons, which, together with the endocannabinoid (eCB) cascades (see below) and possibly the $\mathrm{Na}^{+} / \mathrm{Ca}^{2+}$ exchanger, support the notion that coupling of OXRs to the $\mathrm{G}_{\mathrm{q}} \rightarrow \mathrm{PLC} \beta \rightarrow \mathrm{Ca}^{2+}$ elevation and PKC activation may be of significance also in neurons.

Peripheral signaling is an open question regarding orexin physiology. However, since OXRs appear to be expressed in peripheral tissues, there is at least pharmacological interest [2]. There are several studies demonstrating receptor mRNA and functional responses in peripheral tissues ex vivo $[2,5]$. Other studies have utilized cancer or otherwise immortalized cell lines of peripheral origin $[2,5]$. Whether these cell lines represent their tissue of origin or whether the expression of OXRs is induced by tumorigenesis is unclear. Sometimes the cultured cell lines with their cell culture-induced non-native signaling repertoire may distort the picture, but from our point of view, these cells or cell lines may show interesting signaling properties. It seems reasonable to acknowledge here, the studies investigating OXRs in association with heart function and myocardial protection [55, 56], although the molecular signaling mechanisms remain unknown.

In many cell types, the activation of the phosphoinositide 3-kinase (PI3K) $\rightarrow$ Akt/protein kinase $\mathrm{B}$, is triggered upon OXR activation [2, 4, 5]. Some studies have suggested that Akt signaling drives mammalian target of rapamycin (mTOR) signaling [57], while one study has suggested mTOR activation to be dependent on $\mathrm{Ca}^{2+}$ but independent of Akt [58]. Nevertheless, the mechanism by which PI3K becomes activated upon OXR signaling, the type of PI3K, and the G-protein dependence of this response are unknown.

\section{Orexins and Endocannabinoids}

2-arachidonoyl glycerol (2-AG) is assumed to be the major central nervous system (CNS) eCB. To start this cascade, PLC hydrolyzes phosphatidylinositol-4,5-bisphosphate with arachidonic acid in the sn2-position to generate diacylglycerol, which in turn is hydrolyzed by diacylglycerol lipase (DAGL) to produce 2-AG [59] (Fig. 1). Depending on the 


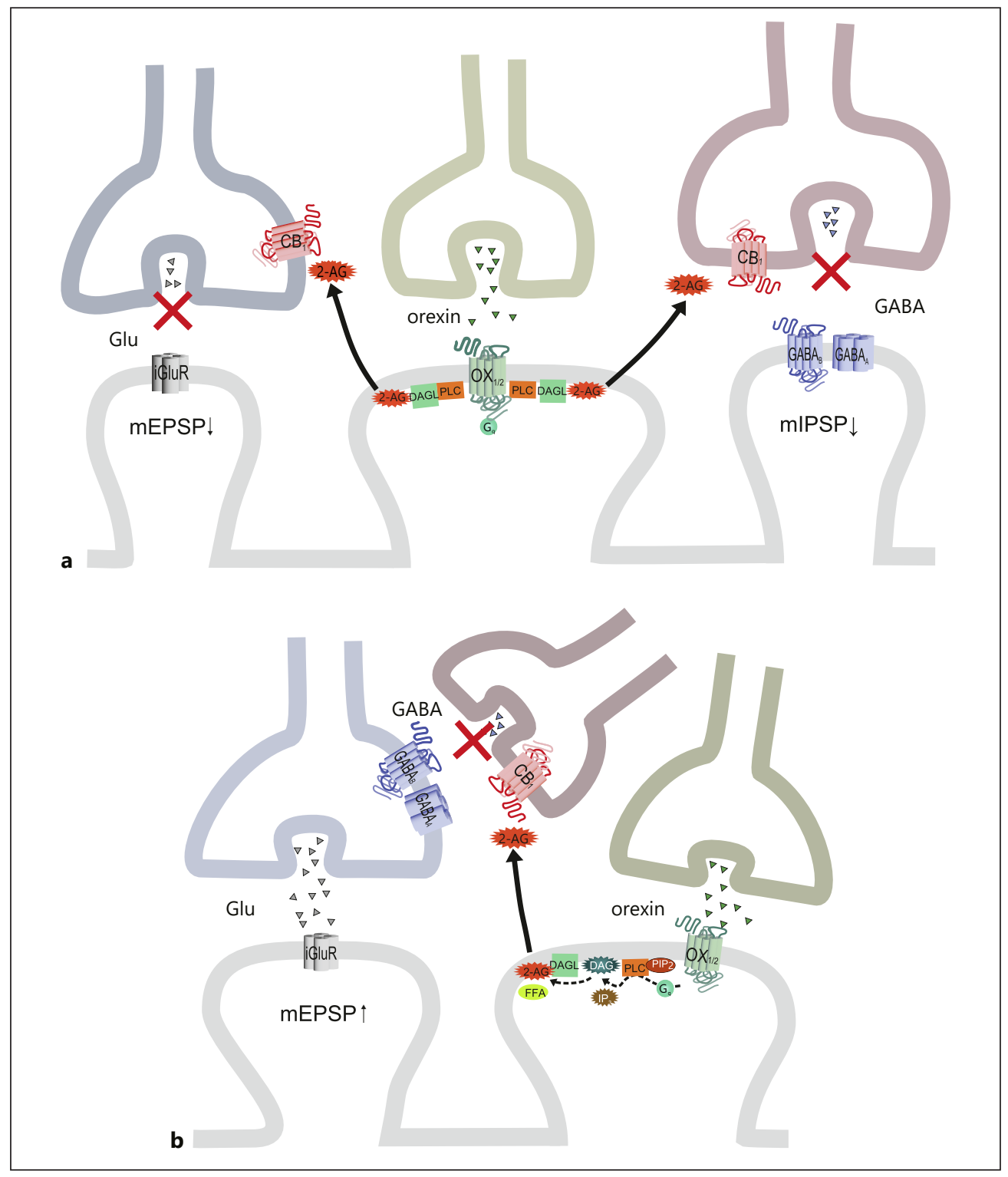

Fig. 1. Schematic representation of the potential 2-AG actions in orexin signaling. a $C_{1} B_{1}$ receptors are directly located on the presynaptic glutamatergic or GABAergic terminals, providing dis-excitation (left) or dis-inhibition (right), respectively, of the orexin target neuron. $\mathbf{b} \mathrm{CB}_{1}$ signaling reduces the inhibitory GABAergic axo-axonal signaling to the stimulatory glutamatergic terminal, increasing glutamate release and the excitatory glutamatergic drive (dis-inhibition of the orexin target neuron). The depicted OXR signal cascades are more briefly abbreviated in $\mathbf{a}$ than in $\mathbf{b}$, but are the same. Note that if the $\mathrm{Cl}^{-}$equilibrium potential was shifted to a more positive potential, the effects of the inhibition of the GABA release would be mEPSP $\downarrow$ both in a (right hand side) and $\mathbf{b}$. 2-AG, 2-arachidonoyl glycerol; $\mathrm{CB}_{1}, \mathrm{CB}_{1}$ cannabinoid receptor; $\mathrm{DAG}$, diacylglycerol; $\mathrm{DAGL}$, diacylglycerol lipase; FFA, free fatty acid (released by DAGL); GABA, gamma-aminobutyric acid; Glu, glutamate; iGluR; ionotropic glutamate receptors; $I_{3}$, inositol-1,4,5-trisphosphate; $\mathrm{mEPSP}$ and mIPSP, miniature excitatory and inhibitory post-synaptic potential (frequency), respectively; $\mathrm{PIP}_{2}$, phosphatidylinositol-4,5-bisphosphate; PLC, phospholipase $\mathrm{C}$. 
synaptic wiring, the outcome of the eCB-signaling varies. The classical response is disinhibition (Fig. 1a, right) [59]. Other potential outcomes are depicted in Figure 1a, left, and Figure 1b. Please observe that, when the $\mathrm{Cl}^{-}$equilibrium potential is above the resting membrane potential, GABA acts as a stimulatory transmitter. The readers are directed to expert reviews in eCBs $[59,60]$.

For OXRs, PLC $\beta$ is likely activated by $\mathrm{G}_{\mathrm{q}}$ and DAGL by $\mathrm{Ca}^{2+}$ elevation. OXR-mediated eCB signaling was first suggested with respect to suppression of glutamate release (disexcitation) in dorsal raphe nucleus [61] and was later supported by findings in additional experimental setups and CNS sites [62-66]. Orexin utilization of eCBs has been frequently reported for neuronal circuits regulating antinociception and reward-seeking, by indirect evidence $[2,4,67]$. One example of antinociception is the dis-inhibition of inhibitory GABAergic tone on descending antinociceptive tracts from the ventrolateral periaqueductal gray matter $[62,66]$. Reward-seeking can be exemplified by the study of Tung et al. [65]: here, dopaminergic neurons of the ventral tegmental area were released from GABAergic inhibition during stress-induced cocaine relapse. Orexinergic neurons have also been suggested to use eCB signaling in an autocrine manner [64].

To date, the only direct demonstration of the OXR signaling cascade via $\mathrm{G}_{\mathrm{q}} \rightarrow$ PLC $\rightarrow$ DAGL $\rightarrow 2-\mathrm{AG} \rightarrow \mathrm{CB}_{1}$ is by us in recombinant $\mathrm{CHO}-\mathrm{K} 1$ cells expressing $\mathrm{OX}_{1 / 2} \mathrm{R}$ combined with artificial retrograde signaling $[20,22,39,68]$. In neurons, the inhibitors used cannot pinpoint PLC, and other OXR-regulated sources of $\mathrm{Ca}^{2+}$ should be considered, such as influx through non-selective cation channels, voltage-gated calcium channels or the $\mathrm{Na}^{+} / \mathrm{Ca}^{2+}$ exchanger, all of which could supply an activation signal for both PLC and DAGL [69]. Diacylglycerol generation via phospholipase D activity [60, 70] has not been ruled out in in vivo systems. In the dorsal raphe nucleus, orexin-B seems to inhibit glutamate release via eCBs even when intracellular $\mathrm{Ca}^{2+}$ elevation is eliminated [61]. Thus, the eCB signaling is probably more complex than presented here. We must also recognize that the physiological regulatory mechanisms of DAGL are not yet established [71].

A number of studies indicate that orexins enhance or suppress miniature excitatory or inhibitory currents [4]. The role of eCBs has seldom been assessed in these cases. Studies utilize tetrodotoxin to inhibit action potentials in presynaptic neurons, which is a logical procedure, but it may yet distort the physiological signal as both the stimulatory and excitatory presynaptic inputs are turned off. The often-utilized synaptic block with low extracellular $\left[\mathrm{Ca}^{2+}\right]$ and high extracellular $\left[\mathrm{Mg}^{2+}\right]$ may also inhibit the eCB generation. Nevertheless, the eCB system (Fig. 1) may be one candidate mediator for at least some of these effects. We should likewise consider the metabolites of 2-AG. 2-AG is hydrolyzed to glycerol and arachidonic acid [72], the latter of which is a messenger in its own right but also a precursor for eicosanoids [69] - which even 2-AG is [73]! 


\section{Cell Death and Survival}

A few research groups, in particular of Drs. Marc Laburthe and Thierry Voisin, have reported OXR-mediated programmed death in immortal cell lines and primary cancer cells $[29,30,74]$. The molecular mechanisms of the cell death are somewhat unclear, as different mechanisms have been reported for different cell types [2, 4]. Nevertheless, the reports of cell death of primary cancer cells are promising [74,75]. A study of pancreatic ductal adenocarcinoma showed, unexpectedly, that both orexin-A and the OXR antagonist almorexant induce death of these cells [75]. The authors suggest almorexant to be a ligandbiased OXR agonist, activating the cell death pathway, while being neutral with respect to the calcium pathway. However, this contradicts their previous finding that both responses are mediated by $\mathrm{G}_{\mathrm{q}}$ [29]. Therefore, the mechanism of almorexant-induced cell death remains unclear.

Other groups have engaged in the research of the role of OXRs in neuroinflammatory and degenerative processes (for examples, see $[76,77]$ ). The effects seen are usually small, and one also has to remember that the published data are often inconclusive as the measurements of mitochondrial respiratory potential do not distinguish between cell proliferation, cell death, and mitochondrial number. With regards to degenerative processes, several studies have identified orexin-A to be neuroprotective in Parkinson's disease (for example, see [78]) but also detrimental to neuronal cells in Alzheimer's disease [79]. As such, it is not surprising that the same receptors can promote both apoptotic and antiapoptotic signals, and we have seen this for $\mathrm{OX}_{1} \mathrm{R}$ in recombinant $\mathrm{CHO}-\mathrm{K} 1$ cells [80]. Nevertheless, it is clearly too early to make conclusions based on these findings. An interesting aspect is that many studies on Parkinson's disease have been conducted using the SH-SY5Y cell line, which is not a dopaminergic but a noradrenergic cell line and represents peripheral sympathetic neurons rather than central neurons. It also remains to be shown whether these cells express OXRs.

\section{Conclusion}

The picture of OXR signaling is more complex than that of many other receptors. We have identified a propensity to signal via several pathways, but we do not quite know which one is important in which type of tissue, i.e. we have not managed to take the leap from the cell lines to native cells. If we wanted, we could do this. Yet, we also do not know many aspects - for example, the identity and regulation of the non-selective cation channels - even in recombinant cells. Plenty of evidence points at a central role of the $G_{q}$ activation in OXR signaling, but much of this is extrapolated, and some effort is required to verify this in native cells. On the cellular lever in the CNS, there is an obvious ability of OXRs to potentiate synaptic signaling. The plastic effects and induction of cell death are well proven, but we would still like to know to which degree they truly represent physiological orexin signaling and, ultimately, what turns the switch to cause either cell survival or cell death. 
How much do we indeed need to know about the cellular OXR signaling before we can put OXR-based medications to the test? We may not need to - and probably never will - understand all the unknown details about OXR signaling outlined in this chapter, but a better insight could certainly be helpful. Quite obviously, if we want to activate OXRs pharmacologically, the first thing we aim at is a synthetic agonist that triggers the same intracellular signaling pathways as the orexin peptides. But is that enough or even preferred, or can we, upon increased knowledge, start aiming at different pharmacological profiles? Clearly, our ambition must be to understand the molecular determinants of OXR signaling as well as the environment-specific determinants, whether that is the postsynaptic density or cancer cells signaling complex, or something else. This approach would serve, equally, the aim of designing novel drugs acting on the orexin system and our understanding of the profound physiological processes.

\section{Key Take-Home Points}

- OXR signaling pathways are complex and apparently utilize different signal transducers in different tissues.

- OXRs are capable of making heteromeric complexes with many other GPCRs in recombinant systems, but whether this happens physiologically is largely unknown. However, if it indeed takes place, it might affect OXR signaling, trafficking, and pharmacology.

- OXR signaling can be investigated with appropriate tools: relevant and characterized inhibitors should be used (there are also plenty of new ones) rather than non-selective and toxic ones, which provide us little useful information. Cascades should be measured directly when possible with appropriate positive and negative controls.

- OXRs appear to stimulate 2-AG release in an efficient manner. Thus far, only a few CNS sites have been assessed for this; we would welcome more.

\section{Conflict of Interest Statement}

J.P.K. received consultancy fees from Idorsia Pharmaceuticals Ltd. during the development of this book. The authors have no other conflicts of interest to declare.

\section{Funding Sources}

The work described was supported by the Magnus Ehrnrooth Foundation, the Liv \& Hälsa Foundation, and Finska Läkaresällskapet.

\section{Author Contributions}

Both authors were involved in the development and review of the chapter, approved the final version to be published, and take responsibility for all aspects of the work. 


\section{References}

1 Kukkonen JP: Recent progress in orexin/hypocretin physiology and pharmacology. Biomol Concepts 2012;3: 447-463.

2 Kukkonen JP: Physiology of the orexinergic/hypocretinergic system: a revisit in 2012. Am J Physiol Cell Physiol 2013;301:C2-C32.

3 Kukkonen JP: Lipid signaling cascades of orexin/hypocretin receptors. Biochimie 2014;96:158-165.

4 Kukkonen JP, Leonard CS: Orexin/hypocretin receptor signalling cascades. Br J Pharmacol 2014;171:294-313.

5 Leonard CS, Kukkonen JP: Orexin/hypocretin receptor signalling: a functional perspective. Br J Pharmacol 2014;171:294-313.

6 Kukkonen JP: Orexin/hypocretin signaling. Curr Top Behav Neurosci 2017;33:17-50.

7 Kukkonen JP: Pharmacology of orexin/hypocretin receptors; in Fadel JR, Burk JA (eds): Functions of Orexins/Hypocretins. Amsterdam, Elsevier, 2019, pp 31-68.

8 Karteris E, Randeva HS, Grammatopoulos DK, Jaffe RB, Hillhouse EW: Expression and coupling characteristics of the crh and orexin type 2 receptors in human fetal adrenals. J Clin Endocrinol Metab 2001;86:4512-4519.

9 Randeva HS, Karteris E, Grammatopoulos D, Hillhouse EW. Expression of orexin-A and functional orexin type 2 receptors in the human adult adrenals: implications for adrenal function and energy homeostasis. J Clin Endocrinol Metab 2001;86:4808-4813.

10 Karteris E, Machado RJ, Chen J, Zervou S, Hillhouse EW, Randeva HS: Food deprivation differentially modulates orexin receptor expression and signalling in the rat hypothalamus and adrenal cortex. Am J Physiol Endocrinol Metab 2005;288:E1089-E1100.

11 Bai B, Chen X, Zhang R, Wang X, Jiang Y, Li D, et al: Dual-agonist occupancy of orexin receptor 1 and cholecystokinin A receptor heterodimers decreases G-protein-dependent signaling and migration in the human colon cancer cell line HT-29. Biochim Biophys Acta Mol Cell Res 2017;1864:1153-1164.

12 Xue Q, Bai B, Ji B, Chen X, Wang C, Wang P, et al: Ghrelin through GHSR1a and OX1R heterodimers reveals a galphas-cAMP-cAMP response element binding protein signaling pathway in vitro. Front Mol Neurosci 2018;11:245.

13 Wang Q, Xiao W, Li Y, Liu Z, Li H, Wang J, et al: Signaling of ghrelin at GHSR1b and OX1R receptor heterodimers. Mol Biol Cell 2019;mbcE19060326.

14 Kukkonen JP: Regulation of receptor-coupling to (multiple) G-proteins. A challenge for basic research and drug discovery. Recept Channels 2004;10:167-183.

15 Kenakin T: Ligand-selective receptor conformations revisited: the promise and the problem. Trends Pharmacol Sci 2003;24:346-354.

16 Kenakin T: Functional selectivity and biased receptor signaling. J Pharmacol Exp Ther 2011;336:296-302.

17 Conibear AE, Kelly E: A biased view of mu-opioid receptors? Mol Pharmacol 2019;96:542-549.

18 Putula J, Turunen PM, Jäntti MH, Ekholm ME, Kukkonen JP: Agonist ligand discrimination by the two orexin receptors depends on the expression system. Neurosci Lett 2011;494:57-60.
19 Rinne MK, Leino TO, Turku A, Turunen PM, Steynen Y, Xhaard H, et al: Pharmacological characterization of the orexin/hypocretin receptor agonist Nag 26. Eur J Pharmacol 2018;837:137-144.

20 Kukkonen JP: G-protein-dependency of orexin/hypocre tin receptor signalling in recombinant Chinese hamster ovary cells. Biochem Biophys Res Commun 2016;476: 379-385.

21 Sakurai T, Amemiya A, Ishii M, Matsuzaki I, Chemelli $\mathrm{RM}$, Tanaka H, et al: Orexins and orexin receptors: a family of hypothalamic neuropeptides and $G$ proteincoupled receptors that regulate feeding behavior. Cell 1998;92:573-585.

22 Kukkonen JP: OX2 orexin/hypocretin receptor signal transduction in recombinant Chinese hamster ovary cells. Cell Signal 2016;28:51-60.

23 Davies SP, Reddy H, Caivano M, Cohen P: Specificity and mechanism of action of some commonly used protein kinase inhibitors. Biochem J 2000;351(Pt 1):95105.

24 Wu-Zhang AX, Newton AC: Protein kinase C pharmacology: refining the toolbox. Biochem J 2013;452:195209.

25 Zeng L, Webster SV, Newton PM: The biology of protein kinase C. Adv Exp Med Biol 2012;740:639-661.

26 Milasta S, Evans NA, Ormiston L, Wilson S, Lefkowitz RJ, Milligan G: The sustainability of interactions between the orexin- 1 receptor and beta-arrestin- 2 is defined by a single C-terminal cluster of hydroxy amino acids and modulates the kinetics of ERK MAPK regulation. Biochem J 2005;387(Pt 3):573-584.

27 Dalrymple MB, Jaeger WC, Eidne KA, Pfleger KD: Temporal profiling of orexin receptor-arrestin-ubiquitin complexes reveals differences between receptor subtypes. J Biol Chem 2011;286:16726-16733.

28 Jaeger WC, Seeber RM, Eidne KA, Pfleger KD: Molecular determinants of orexin receptor-arrestin-ubiquitin complex formation. Br J Pharmacol 2014;171:364-374.

29 Voisin T, El Firar A, Rouyer-Fessard C, Gratio V, Laburthe M: A hallmark of immunoreceptor, the tyrosinebased inhibitory motif ITIM, is present in the G proteincoupled receptor OX1R for orexins and drives apoptosis: a novel mechanism. FASEB J 2008;22:1993-2002.

30 El Firar A, Voisin T, Rouyer-Fessard C, Ostuni MA, Couvineau A, Laburthe M: Discovery of a functional immunoreceptor tyrosine-based switch motif in a 7-transmembrane-spanning receptor: role in the orexin receptor OX1R-driven apoptosis. FASEB J 2009;23: 4069-4080.

31 Duguay D, Belanger-Nelson E, Mongrain V, Beben A, Khatchadourian A, Cermakian N: Dynein light chain Tctex-type 1 modulates orexin signaling through its interaction with orexin 1 receptor. PLoS One 2011; 6:e26430.

32 Rouault AAJ, Lee AA, Sebag JA: Regions of MRAP2 required for the inhibition of orexin and prokineticin receptor signaling. Biochim Biophys Acta Mol Cell Res 2017; 1864:2322-2329. 
33 Alexander SPH, Christopoulos A, Davenport AP, Kelly E, Mathie A, Peters JA, et al: The consise guide to pharmacology 2019/20:G protein-coupled receptors. Br J Pharmacol 2019;176(suppl 1):S21-S141.

34 Medrano M, Aguinaga D, Reyes-Resina I, Canela EI, Mallol J, Navarro G, et al: Orexin A/hypocretin modulates leptin receptor-mediated signaling by allosteric modulations mediated by the ghrelin GHS-R1A receptor in hypothalamic neurons. Mol Neurobiol 2018;55:4718-4730.

35 Wan L, Xu F, Liu C, Ji B, Zhang R, Wang P, et al: Transmembrane peptide 4 and 5 of APJ are essential for its heterodimerization with OX1R. Biochem Biophys Res Commun 2020;521:408-413.

36 Navarro G, Medrano M, Aguinaga D, Vega-Quiroga I, Lillo A, Jimenez J, et al: Differential effect of amphetamine over the corticotropin-releasing factor CRF2 receptor, the orexin OX1 receptor and the CRF2-OX1 heteroreceptor complex. Neuropharmacology 2019;152: 102-111.

37 Wang QQ, Wang CM, Cheng BH, Yang CQ, Bai B, Chen $\mathrm{J}$ : Signaling transduction regulated by 5 -hydroxytryptamine $1 \mathrm{~A}$ receptor and orexin receptor 2 heterodimers. Cell Signal 2019;54:46-58.

38 Navarro G, Quiroz C, Moreno-Delgado D, Sierakowiak A, McDowell K, Moreno E, et al: Orexin-corticotropinreleasing factor receptor heteromers in the ventral tegmental area as targets for cocaine. J Neurosci 2015;35: 6639-6653.

39 Jäntti MH, Putula J, Turunen PM, Näsman J, Reijonen S, Kukkonen JP: Autocrine endocannabinoid signaling potentiates orexin receptor signaling upon CB1 cannabinoid-OX1 orexin receptor coexpression. Mol Pharmacol 2013;83:621-632.

40 Robinson JD, McDonald PH: The orexin 1 receptor modulates kappa opioid receptor function via a JNKdependent mechanism. Cell Signal 2015;27:1449-1456.

41 Chen J, Zhang R, Chen X, Wang C, Cai X, Liu H, et al: Heterodimerization of human orexin receptor 1 and kappa opioid receptor promotes protein kinase A/ cAMP-response element binding protein signaling via a Galphas-mediated mechanism. Cell Signal 2015;27: 1426-1438

42 Milligan G: G protein-coupled receptor hetero-dimerization: contribution to pharmacology and function. $\mathrm{Br} \mathrm{J}$ Pharmacol 2009;158:5-14.

43 Gomes I, Ayoub MA, Fujita W, Jaeger WC, Pfleger KD, Devi LA. G protein-coupled receptor heteromers. Annu Rev Pharmacol Toxicol. 2016;56:403-25.

44 Xu TR, Ward RJ, Pediani JD, Milligan G: The orexin OX1 receptor exists predominantly as a homodimer in the basal state: potential regulation of receptor organization by both agonist and antagonist ligands. Biochem J 2011;439:171-183.

45 Putula J, Pihlajamaa T, Kukkonen JP: Calcium affects OX1 orexin (hypocretin) receptor responses by modifying both orexin binding and the signal transduction machinery. Br J Pharmacol 2014;171:5816-5828.

46 Leino TO, Turku A, Yli-Kauhaluoma J, Kukkonen JP, Xhaard H, Wallen EAA: Azulene-based compounds for targeting orexin receptors. Eur J Med Chem 2018;157: $88-100$.
47 Jäntti MH, Mandrika I, Kukkonen JP: Human orexin/ hypocretin receptors form constitutive homo- and heteromeric complexes with each other and with human CB1 cannabinoid receptors. Biochem Biophys Res Commun 2014;445:486-490.

48 Kukkonen JP: Allosteric interactions via the orthosteric ligand binding sites in a constitutive G-protein-coupled receptor homodimer. Pharmacol Res 2020;105116.

49 Ekokoski E, Aitio O, Tornquist K, Yli-Kauhaluoma J, Tuominen RK: HIV-1 Tat-peptide inhibits protein kinase $\mathrm{C}$ and protein kinase $\mathrm{A}$ through substrate competition. Eur J Pharm Sci 2010;40:404-411.

50 Wang C, Pan Y, Zhang R, Bai B, Chen J, Randeva HS: Heterodimerization of mouse orexin type 2 receptor variants and the effects on signal transduction. Biochim Biophys Acta 2014;1843:652-663.

51 Davies J, Chen J, Pink R, Carter D, Saunders N, Sotiriadis $\mathrm{G}$, et al: Orexin receptors exert a neuroprotective effect in Alzheimer's disease (AD) via heterodimerization with GPR103. Sci Rep 2015;5:12584.

52 Imperatore R, Palomba L, Morello G, Spiezio AD, Piscitelli F, Marzo VD, et al: Formation of OX-1R/CB1R heteromeric complexes in embryonic mouse hypothalamic cells: effect on intracellular calcium, 2-arachidonoyl-glycerol biosynthesis and ERK phosphorylation. Pharmacol Res 2016;111:600-609.

53 Schrage R, Schmitz AL, Gaffal E, Annala S, Kehraus S, Wenzel D, et al: The experimental power of FR900359 to study Gq-regulated biological processes. Nat Commun 2015;6:10156.

54 Kukkonen JP: G-protein inhibition profile of the reported Gq/11 inhibitor UBO-QIC. Biochem Biophys Res Commun 2016;1:101-107.

55 Perez MV, Pavlovic A, Shang C, Wheeler MT, Miller CL, Liu J, et al: Systems genomics identifies a key role for hypocretin/orexin receptor-2 in human heart failure. J Am Coll Cardiol 2015;66:2522-2533.

56 Patel VH, Karteris E, Chen J, Kyrou I, Mattu HS, Dimitriadis GK, et al: Functional cardiac orexin receptors: role of orexin-B/orexin 2 receptor in myocardial protection. Clin Sci (Lond) 2018;132:2547-2564.

57 Chang X, Suo L, Xu N, Zhao Y: Orexin-A stimulates insulin secretion through the activation of the OX1 receptor and mammalian target of rapamycin in rat insulinoma cells. Pancreas 2019;48:568-573.

58 Wang Z, Liu S, Kakizaki M, Hirose Y, Ishikawa Y, Funato $\mathrm{H}$, et al: Orexin/hypocretin activates mTOR complex 1 (mTORC1) via an Erk/Akt-independent and calcium-stimulated lysosome v-ATPase pathway. J Biol Chem 2014;289:31950-31959.

59 Kano M, Ohno-Shosaku T, Hashimotodani Y, Uchigashima M, Watanabe M: Endocannabinoid-mediated control of synaptic transmission. Physiol Rev 2009;89: 309-380.

60 Muccioli GG: Endocannabinoid biosynthesis and inactivation, from simple to complex. Drug Discov Today 2010;15:474-483.

61 Haj-Dahmane S, Shen RY: The wake-promoting peptide orexin-B inhibits glutamatergic transmission to dorsal raphe nucleus serotonin neurons through retrograde endocannabinoid signaling. J Neurosci 2005;25:896-905. 
62 Ho YC, Lee HJ, Tung LW, Liao YY, Fu SY, Teng SF, et al: Activation of orexin 1 receptors in the periaqueductal gray of male rats leads to antinociception via retrograde endocannabinoid (2-Arachidonoylglycerol)-induced disinhibition. J Neurosci 2011;31:14600-14610.

63 Lee HJ, Chang LY, Ho YC, Teng SF, Hwang LL, Mackie $\mathrm{K}$, et al: Stress induces analgesia via orexin 1 receptorinitiated endocannabinoid/CB1 signaling in the mouse periaqueductal gray. Neuropharmacology 2016;105: 577-586.

64 Morello G, Imperatore R, Palomba L, Finelli C, Labruna $G$, Pasanisi F, et al : Orexin-A represses satiety-inducing POMC neurons and contributes to obesity via stimulation of endocannabinoid signaling. Proc Natl Acad Sci USA 2016;113:4759-4764.

65 Tung LW, Lu GL, Lee YH, Yu L, Lee HJ, Leishman E, et al: Orexins contribute to restraint stress-induced cocaine relapse by endocannabinoid-mediated disinhibition of dopaminergic neurons. Nat Commun 2016;7: 12199.

66 Chen YH, Lee HJ, Lee MT, Wu YT, Lee YH, Hwang LL, et al: Median nerve stimulation induces analgesia via orexin-initiated endocannabinoid disinhibition in the periaqueductal gray. Proc Natl Acad Sci USA 2018; 115:E10720-E10729.

67 Berrendero F, Flores A, Robledo P: When orexins meet cannabinoids: bidirectional functional interactions. Biochem Pharmacol 2018;157:43-50.

68 Turunen PM, Jäntti MH, Kukkonen JP: OX1 orexin/ hypocretin receptor signaling via arachidonic acid and endocannabinoid release. Mol Pharmacol 2012;82:156167.

69 Kukkonen JP: A ménage à trois made in heaven: G-protein-coupled receptors, lipids and TRP channels. Cell Calcium 2011;50:9-26.

70 Jäntti MH, Putula J, Somerharju P, Frohman MA, Kukkonen JP: OX1 orexin/hypocretin receptor activation of phospholipase D. Br J Pharmacol 2012;165:1109-1123.

71 Bisogno T, Howell F, Williams G, Minassi A, Cascio MG, Ligresti A, et al: Cloning of the first sn1-DAG lipases points to the spatial and temporal regulation of endocannabinoid signaling in the brain. J Cell Biol 2003;163: 463-468.
72 Savinainen JR, Saario SM, Laitinen JT: The serine hydrolases MAGL, ABHD6 and ABHD12 as guardians of 2-arachidonoylglycerol signalling through cannabinoid receptors. Acta Physiol (Oxf) 2012;204:267-276.

73 Urquhart P, Nicolaou A, Woodward DF: Endocannabinoids and their oxygenation by cyclo-oxygenases, lipoxygenases and other oxygenases. Biochim Biophys Acta 2015; 1851:366-376

74 Voisin T, El Firar A, Fasseu M, Rouyer-Fessard C, Descatoire V, Walker F, et al: Aberrant expression of OX1 receptors for orexins in colon cancers and liver metastases: an openable gate to apoptosis. Cancer Res 2011;71: 3341-3351.

75 Dayot S, Speisky D, Couvelard A, Bourgoin P, Gratio V, Cros J, et al: In vitro, in vivo and ex vivo demonstration of the antitumoral role of hypocretin-1/orexin-A and almorexant in pancreatic ductal adenocarcinoma. Oncotarget 2018;9:6952-6967.

76 Duffy CM, Nixon JP, Butterick TA: Orexin A attenuates palmitic acid-induced hypothalamic cell death. Mol Cell Neurosci 2016;75:93-100.

77 Kong T, Qiu K, Liu M, Cheng B, Pan Y, Yang C, et al: Orexin-A protects against oxygen-glucose deprivation/ reoxygenation-induced cell damage by inhibiting endoplasmic reticulum stress-mediated apoptosis via the $\mathrm{Gi}$ and PI3K signaling pathways. Cell Signal 2019;62: 109348.

78 Liu MF, Xue Y, Liu C, Liu YH, Diao HL, Wang Y, et al: Orexin-A exerts neuroprotective effects via OX1R in Parkinson's disease. Front Neurosci 2018;12:835.

79 Li M, Meng Y, Chu B, Shen Y, Liu X, Ding M, et al: Orexin-A aggravates cytotoxicity and mitochondrial impairment in SH-SY5Y cells transfected with APPswe via p38 MAPK pathway. Ann Transl Med 2020;8:5.

80 Ammoun S, Lindholm D, Wootz H, Åkerman KE, Kukkonen JP: G-protein-coupled OX1 orexin/hcrtr-1 hypocretin receptors induce caspase-dependent and -independent cell death through p38 mitogen-/ stress-activated protein kinase. J Biol Chem 2006;281: 834-842.
Jyrki P. Kukkonen

Department of Pharmacology

Institute of Biomedicine, Faculty of Medicine, University of Helsinki

Helsinki (Finland)

jyrki.kukkonen@helsinki.fi 